\title{
Viewpoint
}

\section{On the history and future of $O R$}

Journal of the Operational Research Society (2007) 58, 832-835. doi:10.1057/palgrave.jors.2602324

I read Jackson's paper (Jackson, 2006) with interest but was disappointed that 'a reinvention of the future of OR/MS' turned out to be a recycling of old myths and prejudices and a platform for once again promoting his own approach, his particular variant of critical systems theory (CST), an approach which has been around for 20 years or so.

In brief, Jackson's paper sets out to describe how OR/MS lost its way, how with PSMs (problem structuring methods) in the vanguard OR/MS is in a much better position to realize its original ambitions, and how a pluralist approach overseen by CST can take this progress forward. The paper favours a theoretical evaluation leaving practical investigations to be conducted by others. The theoretical analysis is pursued in three phases: the first phase traces the evolution of OR/MS and applied systems thinking over the last 50 years; the second and third phases examine different strands of OR/MS and applied systems thinking.

In outlining the history of OR/MS in his first phase, Jackson is keen to establish the failure of OR/MS to achieve the original ambitions of the pioneers. He turns for evidence to the literature, which is dominated by academics whose purpose in life is to be critical with the laudable aim of, in some way that they individually think desirable, improving the situation. However, the fact that an academic writes something down does not make it true, and there is a danger that constant repetition of the views of a few vociferous academics produces a distorted picture. Jackson also adds in a few distortions of his own and I believe the resulting narrative is at best unbalanced. He then uses his flawed historical narrative to point OR/MS in an overly narrow direction.

\section{Myths and distortions}

The historical narrative starts with the ambitions of the pioneers which some commentators in the 1970s and 1980s felt were not being met. There may be some truth in this but it is a very partial truth. The other story which could be told is that by this time OR/MS had been hugely successful in establishing practice in the military, industrial, commercial and, to a degree, governmental domains. Academic activity was also being established in many Universities. This could be viewed as a high point in the profession's history. At the time I was working at the Operational Research Executive (ORE) of the National Coal Board (NCB), a group of over 100 scientists. I will use this experience to illustrate just how far off the mark Jackson's characterizations are:

1. The ambitions of the pioneers had not been met: the existence of ORE, a large group conducting a wide variety of research, would surely have exceeded the expectations of many of the original pioneers who could not have been sure that OR would survive at all. The fact that thriving OR groups existed in military, industrial, commercial and governmental settings was a substantial achievement. Certainly the pioneers had great ambitions for OR's contribution to society and not everybody's hopes were being met, but different people have different ideas about how society can be improved (some might want to improve medical services for the poor and old, others might want to help companies become more effective and grow, others might want to maximize the country's military potential).

2. Degeneration into mathematical modelling: Jackson characterizes OR at the time as naïve optimization against a single objective. The OR scientists within ORE worked on broadly based research programmes. Much of the work did not involve the use of standard techniques at all. The most commonly used techniques were simulation, forecasting and statistics, none of which involved optimization against a single objective. A major attempt had been made to use LPs for planning machinery usage but was abandoned before my time. There had been some small use made of LPs to design blends of coal stocks for the market. However, the remaining applications of LPs were, as I remember it, all in the area of work for which I was responsible. These were built to understand the underlying structure of markets and the impact of investment and technology, not used to take decisions. One model was used to calculate shadow prices through time to be used in the Board's investment decision process. There was never any question of determining optimum decisions. (Plackett et al, 1982).

3. The 'new paradigm' is concerned with learning not optimization: actually traditional OR was concerned with research not optimization. Research embraces learning by researchers and clients alike but also includes the encoding (in reports and models) and dissemination (for instance, training managers in the application of an approach) of a body of researched knowledge (I am talking here about client-specific knowledge). Some OR research programmes at ORE continued for over 15 years adapting to new circumstances, addressing new aspects of the 'swamp' of reality. 
4. Traditional OR does not address uncertainty: the acceptance of uncertainty is depicted by Jackson as a feature of the 'new paradigm of analysis' diametrically opposed to traditional OR. In fact, addressing uncertainty was central to traditional OR. In a paper in 1983, I characterized the three major categories of uncertainty for the NCB as geological, operational and business (Ormerod, 1983). The main thrust of the OR contribution was to provide operational gaming to help managers and engineers understand the consequences of geological uncertainty (Sloman, 1977), simulation models for addressing operating uncertainty in the design and operation of coal clearance and preparation systems (Gregory and Russell, 1973), and 'what ... if' models for exploring business uncertainty in the national and international energy markets (Harrison and Baker, 1974; Plackett et al, 1982).

5. $[O R]$ failed to establish itself at the strategic level in organizations: this is simply not the case as demonstrated by my own experience as reported by Derek Ezra, the Chairman of the NCB, to the Royal Society (Ezra, 1977). The strategic nature of the applications can be judged from Plackett et al (1982) and Ormerod and McLeod (1983).

6. Aware practioners deviated from the textbook representation of management science: this is the wrong way round. In reality, OR practitioners practise, and always have practised, as they see fit; textbooks either capture or deviate from this practice.

Of course, these are based on my particular experiences in the energy sector but they appear not to be too dissimilar to reports from other sectors. For instance, in 1978 Robin Leigh-Pemberton, Chairman of National Westminster Bank, demonstrated his support for OR in banking in a Blackett Memorial Lecture (Leigh-Pemberton, 1979). In 1979, Boldy and Clayden reported that a comparison over the period 1972 and 1977 of Health and Welfare OR in the UK and Ireland showed that the focus had moved away from tactical studies 'towards more broadly-based strategic studies' (Boldy and Clayden, 1979). In 1980 John Biffen, Chief Secretary to the Treasury, said 'This is the first opportunity I have had since becoming a Treasury Minister of discussing with a professional audience the contribution that their particular discipline [OR] makes to the work of the Treasury' (Biffen, 1980). Also in 1980, Tobin, Rapley and Teather related the experience of the OR Branch of British Airways (Tobin et $a l, 1980)$ observing that the introspection at that time sometimes appeared distorted; they concluded that 'gloom is not warranted'.

Thus, we have two possible stories for $O R$ in the 1970s-one gloomy, the other more optimistic. Can they be reconciled? In 1981, Whiteman and Wise described the evolution of OR in National Westminster Bank in terms of 'stages' in the growth of an OR Group: birth, childhood, adolescence and adulthood (Whiteman and Wise, 1981). They noted that reliance on techniques had been greatly reduced in the later stages. Applying the model more widely to European banks they concluded that a small number of large 'mature and successful' groups 'see themselves as having a major role in tackling the larger unstructured problems of their banks'. Further, '[t]he groups see themselves as clarifying the key issues through a variety of logical/analytical methods (not necessarily those of classical OR), recognizing the importance of multiple objectives and the need to challenge widely held prejudices that may not be evidence based'. (p 531). In contrast a substantial number of small groups adopting 'the arrested development approach' had found a niche in their organization 'doing technical support work on their organizations but, by staying small and doing useful work, they have survived'. (p 529). Assuming this pattern was repeated in other industries, OR practice at the time was made up of a small number of large broadly based mature groups together with a large number of small technically orientated niche groups. It suited academics of the day to ignore the large mature groups.

\section{Management and power}

Jackson has somehow to square his view of management (his commitment to undermine their power) with his role as Dean of a business school. He does seem to be attempting to do this at times but old habits die hard: describing the history of OR he says ' $[\mathrm{OR}]$ transmogrified into management science and away from a science dedicated explicitly to the general good'. Even if it were true that OR was solely about management (not a view I would share), surely in a society based on democratic welfare capitalism management science is entirely consistent with being dedicated to the general good. More broadly better management of companies, public organizations, not-for-profit organizations, and community, interest and other groups, within the developed or less developed societies, whether based on capitalism or central planning, is for the general good. In the paper, Jackson develops a false opposition between better management and the general good.

Jackson's favoured philosophical position, critical theory, sees management as control by an elite. He has recently said that he is not going to apologize for taking Marxist theory seriously (Jackson, 2005), and nor should he. What he should do is be prepared to debate how his Marxist (or neo-Marxist) stance manifests itself in the approach to OR that he advocates. He has made a cornerstone of his version of a critical systems thinking (CST) a commitment to emancipation, meaning a commitment to challenge inequalities of power, to champion the less powerful, to free people from the constraints imposed by power relations. It sounds good and no doubt makes those so committed feel worthy, but it takes no account of reality. Organizations, except in the most extreme ideal case of those run on perfectly democratic lines, cannot operate without the exercise of power. In most organizations power to decide is placed in the hands of people usually 
designated managers (or executives, directors, board members, etc). There will be social, legal and democratic contextual factors influencing their decisions, and there will be consultations, seeking of advice and sometimes public enquiries, but in the end decisions will be taken by someone or a group of people to commit the resources of the enterprise or not. Thus, power is exercised: organizational life depends on the frequent exercise of power. In the case of a private company, there will be many stakeholders (with varied interests) and there may be many others affected by the decision, but undoubtedly the interest of shareholders will loomlarge.

There will be inequalities of power in practically all cases. That this should be so is because we live in a society which is essentially based on democratic welfare capitalism, not on either pure democracy nor pure socialism. In such a society there are various laws relating to ownership, contract, intellectual property, employment, health, safety, tax, planning, environmental impact and so on. Companies are legal entities which employ managers to pursue the owners' legitimate interests (with all sorts of checks and balances). Other parties also have legitimate interests in the decisions of the managers but not usually the same power to decide and act. Public enterprises are subjected to a somewhat different mix of powers as the public (citizens') interest is more prominent and immediate. All this is, of course, obvious except that Jackson's approach involves a commitment to oppose the legitimate power imbalances in these democratically endorsed forms of enterprise; he is against management. That's up to him, of course. In a recent exchange Jackson says that he is "in favour of planning, organising and controlling" and is simply "against the misuse of managerial power" (Jackson, 2005). So are we all. But what specifically is Jackson referring to here? How can he be both against inequalities of power and for managerial control? How does a manager control without exercising power? What does he define as misuse?

\section{OR theory and practice}

More encouragingly Jackson talks about bridging the gap between theory and practice. But his approach is to opt for a theoretical evaluation, leaving practical investigations to be conducted by others. Worse, his chosen bridge is highly theoretical:

methodology can provide the bridge between theory and practice, ensuring that theory is turned into practical action and allowing refection back on theory, stemming from the results of that action.

Methodologies, Jackson explains, are more theory impregnated than methods. Thus, the bridge to practice is to be built with yet more theoretical theories and without reference to practice: not very encouraging. The above quote also shows that Jackson still has not embraced the idea that theory can be derived from practice: in his view of the world it is always the other way round, theory is turned into practical action. The development out of practice of both SSM and SCA (strategic choice analysis) are conveniently forgotten. No progress here then.

\section{Reinventing the future of OR/MS}

Jackson's chosen tool for evaluating PSN's and demonstrating the direction of intellectual activity in OR/MS is the system of systems methodologies (SOSM). Whatever the merits of the particular characterizations used in the framework (see Ulrich, 2003 for a recent criticism) it has been let down by the way it has over time been used and abused: this paper is no different.

The paper's historical narrative using the SOSM depicts classical OR/MS occupying the unitary/simple box until pioneering movements were made into the unitary/complex box by systems dynamics and into the pluralist/simple box by PSMs. This is historically incorrect: OR necessarily occupied all six boxes. It could not do otherwise as all six boxes depict aspects of reality characteristic of all situations. To illustrate the point I can simply cite my own experiences of corporate, national and international energy analysis, modelling and policy formulation as briefly set out in a recent Viewpoint (Ormerod, 2006b) and more fully in Ezra (1977), Ormerod (1980 and 1983) and Plackett et al (1982). What could be more coercive than the energy scene in the late 1970s and early 1980s? Not only did OR de facto occupy all six boxes; there were already specific methods being used by OR practitioners in most if not all of the boxes. For instance, simulation was widely used and I imagine it sits in the unitary/complex box; decision conferencing, scenario planning, Delphi, strategic choice analysis (SCA) and multi-criteria decision making (MCDA) would have sat somewhere in the pluralistic boxes; and metagame theory would have sat in the coercive boxes. SCA, for instance, finds its origins in the Institute for Operational Research (IOR), which was set up in 1963. The first book on SCA was published in 1969 (Friend and Jessop, 1969). Another example is the energy game that we ran three times a year at the NCB staff college (Ormerod and McLeod, 1983). The game helped participants understand the different (pluralistic) points of view of the various energy industries and the (coercive) leverage each could exert. Thus, within the history of OR, PSMs such as soft systems methodology and cognitive mapping can be seen, not in terms of providing a vanguard leading a breakout from the unitary/simple box, but as part of OR's general advance of understanding and codification in each of the boxes.

I believe a more realist and inspiring view of the future of OR would anticipate advances (by multiple vanguards) in many different areas of OR endeavour both in practice and academia. I have outlined just some of these in the strategic domain in a previous Viewpoint (Ormerod, 2006a). A wider consideration of all the subject domains of OR would generate a much longer list (many more vanguards). For instance, I would regard Van Wassenhove, 2006 Blackett lecture as 
potentially leading to path breaking applications in humanitarian aid logistics (Van Wassenhove, 2006).

\section{References}

Biffen J (1980). Management and control of public expenditure. J Opl Res Soc 31: 1059-1061.

Boldy D and Clayden D (1979). Operational research projects in Health and Welfare Services in the United Kingdom and Ireland. J Opl Res Soc 30: 505-511.

Ezra D (1977). Operational research within the National Coal Board. Phil Trans $R$ Soc Lond A 287: 467-486.

Friend JK and Jessop WN (1969). Local Government and Strategic Choice: An Operational Research Approach to the Processes of Public Planning. Tavistock: London.

Gregory K and Russell C (1973). SIMPREP, a computer model for Coal Preparation. In: Ross M (ed). OR '72. North Holland: Amsterdam.

Harrison FB and Baker A (1974). The accountant takes to models. Some experiences in NCB Coal Products Division. Opl Res $Q 25$ : $3-18$.

Jackson MC (2005). Sexing-up the evidence: A reply to Ormerod and Ulrich Viewpoint. J Opl Res Soc 56: 467-468.

Jackson MC (2006). Beyond problem structuring methods: Reinventing the future of OR/MS. J Opl Res Soc 57: 868-878.

Leigh-Pemberton R (1979). OR and the changing banking scene. J Opl Res Soc 30: 1-9.

Ormerod RJ (1980). Energy models for decision making. Eur J Opl Res 5: 366-377.

Ormerod RJ (1983). Corporate planning and its use of OR in the NCB: A personal view. J Opl Res Soc 34: 461-467.

Ormerod RJ (2006a). The OR/MS contribution to strategy development and policy-making. Viewpoint. J Opl Res Soc 57: $117-121$.

Ormerod RJ (2006b). The OR approach to forecasting: Comments on Mingers' paper. Viewpoint. J Opl Res Soc 57: 1371-1373.

Ormerod RJ and McLeod J (1983). The development and use of the NCB Strategic Model. The Statistician 33: 35-49.

Plackett MW, Ormerod RJ and Toft F (1982). The National Coal Board Strategic Model. Eur J Opl Res 10: 351-360.

Sloman M (1977). How operational gaming can help with the introduction of new technology. Opl Res $Q$ 28: 781-793.

Tobin NR, Rapley K and Teather W (1980). The changing role of OR. J Opl Res Soc 31: 279-288.

Ulrich W (2003). Beyond methodological choice: Critical systems thinking as critically systems discourse. J Opl Res Soc 54: $325-342$.

Van Wassenhove LN (2006). Blackett Memorial Lecture. Humanitarian aid logistics: Supply chain management in high gear. J Opl Res Soc 57: 475-489.

Whiteman RP and Wise PJS (1981). Lessons for OR from the world of banking. J Opl Res Soc 32: 519-534.

Warwick University, Coventry, UK

RJ Ormerod

\section{Reply to Ormerod}

Journal of the Operational Research Society (2007) 58, 835. doi:10.1057/palgrave.jors.2602325

I will make just three short points in response to Ormerod's 'viewpoint' (Ormerod, 2007).

1. Myths and distortions: If OR/MS had realized the ambitions of many of its pioneers it would, today, be central to matters such as improving the effectiveness of our public services, strategic decision-making in major corporations and campaigns to end world poverty. There would be no need for initiatives such as 'community OR', to revitalize theory and practice, and the 'science of better' to broadcast what OR/MS can achieve. OR/MS has failed to deliver on what were admittedly the high aspirations of some of its influential founders.

2. Management and power: Ormerod insists on representing me as some sort of unreconstructed Marxist and reading everything through that lens. I wish he would pay attention to what I write (eg Jackson 2000, 2003) and re-evaluate his prejudices. I could make the same detailed response here that I have already made in a previous reply to Ormerod (Jackson, 2005).

3. Reinventing the future of $O R / M S$ : I am sure OR/MS has to occupy 'all six boxes'. The problem is that its traditional methodologies and methods were tailored specifically to the unitary/simple box. Brave souls have sought to 'break out' of this box, to make OR/MS more suitable for dealing with complexity, pluralism and conflict. Their endeavours, I argue in my paper, can be made more efficient and effective if they receive appropriate theoretical support from a range of social science paradigms.

\section{References}

Jackson MC (2000). Systems Approaches to Management. Kluwer/ Plenum: New York.

Jackson MC (2003). Systems Thinking: Creative Holism for Managers. Wiley: Chichester.

Jackson MC (2005). Sexing-up the evidence: A reply to Ormerod and Ulrich. J Opl Res Soc 56: 467-468.

Ormerod RJ (2007). On the history and future of OR. J Opl Res Soc 58.

Hull University, Hull, UK

MC Jackson 